\title{
Agro-Production Grouping of the Soils under Forests and Woodless Areas of Shamakhi in Azerbaijan
}

\author{
Ulviyya Mammadova
}

Department of Soils Ecology and Bonitation, Institute of Soilscience and Agrochemistry of ANAS, Baki, AZ1073, Azerbaijan

\begin{abstract}
Soil study and agro-producing grouping was carried out in Shamakhi region of Azerbaijan. Due to the soil study carried out in the territory step by step bonitation process was realized. Research concerns to the forest soils and woodless soils in the zone. On the base of the bonitation as the summarizing stage agro-producing grouping was fulfilled. Ecological estimation of soils under forest and woodless aread has been implemented. Finally four agro-producing groups were determined on the fertility indexes and their area square was revealed within each soil contour.
\end{abstract}

Keywords Agro-Producing Grouping, Bonitation, Open Bonitation Scale, Final Bonitation Scale

\section{Introduction}

In the paper agro-production grouping was established for the soils under forest and woodless areas of Shamakhi was looked though. On the basis valuation the scale was established for the soils under forest and woodless areas of Shamakhi. They were divided into 4 forest production groups. Soil bonitation realization is the proceeding of the new processes. Because fruitful soil usage organization and soil fields' specify suiting to the considered criterion validates soil decent utilization in both agriculture field and the other fields. From the purpose of the study, usually as the prolongation of the bonitation agro-production or forest-production grouping is carried out[2,4,5]. These grouping gives opportunity increasing of crop-producing power and initial managerial procedure beforehand. Plant formation study in the studying region promotes the result of the investigation. Taking into consideration genetic generation singularities complex and specific argo-productive grouping can be actualized. After having fulfilled soil bonitation in the studying region on the base of the bonitation points agro-producing grouping may be implemented. Majorly during land reserves accounting by using complex patterns and factors of their taxonomic units agro-producing grouping is brought into effect. At the same time in this field enough researches were carried out from the beginning of the former centaury. While agro- irrigative and irrigative projecting in agriculture specific agro-producing was needed. In its turn this is included to the increasing of the agriculture plants' productivity[4,6,11,12]. Specific agro-producing grouping is

* Corresponding author:

uf_samadova@yahoo.com (Ulviyya Mammadova)

Published online at http://journal.sapub.org/env

Copyright (C) 2012 Scientific \& Academic Publishing. All Rights Reserved established taking into account soil erosion, soil salinization and other factors, soil states generalizing soil taxonomic units. Variety of the natural climate condition and soil foundation in the Republic has great influence on the agriculture development. In this case this deeds' realization is necessary in order to build all processes for enhancing effectiveness. I should notice that from $1940^{\text {th }}$ years in this direction large researches have been carried out. In $70^{\text {th }}$ years the southern-west part of Azerbaijan significant investigation was implemented by Sh.G.Hasanov (1972). Researcher studied the regularity relation between agricultural plants and soil quality showings. Dr. Hasanov established bonitaion scale and cartogram of eight regions. In the cartogram soil contours were expressed by points and point classes. In $70-80^{\text {th }}$ soil bonitation was fulfilled covering different agricultural plants and various regions' soils, but there was the unique reason in all investigations. Common scheme of these works was so:

- Selection of estimating criterions and etalon soil in the studying area;

- Development of close bonitation scale on the base of mathematical calculations by using estimating criterions;

- Determination of correction coefficient by using correlative relation between agricultural plants' productivity and soil erratic showings;

- Establishment of the open bonitation scale by applying correction coefficients;

- Realization of agro-producing grouping on due to the point of the soil kind variety;

- Establishment of bonitation cartogram for the studying area.

At the current time the deeds being done within this scheme is called "traditional bonitation" in Soil Science. The initial dissertation theme in the field of forest soils bonitation (F.L.Piriyeva, 1984; S.R.Tagiyev, 1991) was defended by Dr. 
F.L.Piriyeva. studying the south slope of the Great Caucasus she determined the internal properties of the woodland soils, used them as the estimating factors and correction coefficients and finally compiled bonitation scale of the area. The other research work was carried out on the northen-west part of the Great Caucasus by S.R.Tagiyev. Firstly he received granulometric content as the estimation factor but not correction coefficient.

Academician G.Mammadov proposed initially agroproducing and forest-producing grouping implementation to the bonitation points[3-6]. Since $90^{\text {th }}$ years till today soil scientists have been utilizing in the researches.

\section{Object and Methods of the Study}

Pirgulu has very small area which is the studying object. Therefore bonitation of all soils under woodland and soils without woodlands od Shamakhi region was carried out. This region is the important zone not alny for agriculture but also for forestry. The main scope of the research is the studying the ecological state of the soils under the forest and soils without woodland[8,10]. Commonly forest soils total square in Shamakhi region is more than 59528,89 ha. Whilst forestation and afforestation process agro-producing grouping is more necessary for selecting tree kinds and revealing soil state in the territory. The major synfolium consists of hornbeam, oak, beech trees. On the north slope of Pirgulu mountain hornbeam (Carpinus) forests with 25-40 years old extended. During forest hewing the survived trees old reach to $120-160$ years. On the low- reclining south slope of Pirgulu mountain after forest hewing process complex structured and ladder-shaped woodland appeared. And on the vertical southern slope pure oak forest with gew (Taxus) coverage spread out. There're partly included birch (Betula), ash (Fraxinus), hornbeam (Carpinus) and other tree species within the woodland. Here gew (Taxus) groups cover 50-60\% of the territory. The forest by name "Janut" located near Pirgulu State Natural Preserve is the gew woodland with the largest square not only in Shamakhi region but also all over the Republic. As the result of the long term soil bonitation researches due to the soil fertility indexes agro-producing grouping is realized by selecting suitable bonitation points. This lets to determine soils having same quality. In soil bonitation agro-producing grouping is considered to classify soils having same bonitation indexes on the classes. For realizing common and specific agro-producing grouping new method has more advantages than the old one which was carried out on the genetical- production characteristics $[5,7,9]$. According to the forest formation tree species' demand for forestation in the specific agro-producing grouping groupage is established on the base of soil taxonomic units' bonitation indexes.

Lately in forestation and reforestation this type bonitation is advisable. But in this field the researches on a large scale should be done. Unlike the specific agro-producing grouping, common agro-producing grouping is actualized to the soil internal diagnostic pequliarities but not due to the particular tree or plant species' demand. In such agro-producing grouping there is extensive opportunity to bring into effect the forestation process fruitfully and effectively. At present in efficient forest plantation and forest regeneration both type agro-producing grouping implementation is substantial. After academician G.Sh.Mammadov put forward the idea in which bonitation indexes are taken into consideration, in this field the durational researches have been carried out. Bonitation method is widely used not only for fundamental investigation of woodland soils but also for soils under crop, pasture ground and other farms. The final or summarizing, so in generalizing stage land field, laboratory study implementation of the soils, systematizing plant production information and estimation have to be actualized. The following works are done on the base of soil fertility indexes, mechanical contents' showing factor:

- Determination of the final point of typical or normal soils distinguished with their characteristics (salinization, salification, erosion, cultivation ability and so on.) by applying correction coefficient (the lowest taxonomical level);

- Establishment of the large bonitation scale of the studying area on its base;

- Realization of agro-producing (forest-producing) grouping of the areas by revealing average rated point;

- Determination of the comparative value coefficient of the spoils;

- Establishment of agro-producing and bonitation cartogram of the studying areas;

- All the works are separately fulfilled.

While compiling the main bonitation scale for soil type and soil subtype, correction coefficient of soil characteristics for soil properties and features, then the bonitation indexes of soil kinds are revealed in the lowest taxonomic units in the studying area (farm, region, natural-economical region and so on)

The following formula is used for this purpose:

$$
B_{k}=B_{t} \cdot K_{\text {salification }} \cdot K_{g} \cdot K_{\text {soft }} \cdot K_{\text {stoniness }} \cdot K_{c}
$$

Here $B_{k}$ - bonitation indexof the soil kind varity, $B_{t}$ bonitation index of soil type and subtype; $K_{\text {salification }}$ - correction coeffient of salification, $K_{g}$ - corection coeffient of granulometric content; $K_{\text {soft }}$ - corecsion coefficient of the soft layer thickness; $K_{\text {stoniness }}$-corecsion coefficient of stoniness, $K_{c}$ - is coefficient of culture level and so on.

So, within the studying area (farm, region or zones) bonitation index and the square of each contours hectare of all soil kind varity can be determined. Due to these data the open bonitation scale and the final bonitation scale of the soil type and subtype are to be established. During preparing such scales all soils bonitation indexes are aligned to the ablatitious lines. The bonitation of the area (farm, region or natural-economical zone) doesn't reach with the establishment of the open bonitation scale.

The major reason is that tree pr four pecularities (humus, 
common nitrogen, phosphorus, SAM - sum of absorbed matters) are necessary for bonitation process. The main scale of the "normal" soils can't show the effective state of the area soils.

In other parts I defined that there is no normal soil in the nature. All soils have definitively undergone erosin, salination, salification, salting, paludification, stoniness, non fruitful granulometric content. Sometimes at the result of human-being soils fertility are improved. Whole these finally can't effect to the bonitation indexes in the main scale of the soils. That's why in cameral-treatment stage the main scale established due to the reference and fund materials was developed on the next stage studies, the summarized bonitation scales were processed.

The total bonitation index of soil type and subtype is calculated on the base of soil kind varity bonitation index and square showings. For this the following formula is utlized:

$$
B=a_{1} \cdot k_{1}+a_{2} \cdot k_{2}+a_{3} \cdot k_{3}+\ldots \ldots . . / \text { Square }
$$

Here, $B$ - final bonitation index of soil type and soil subtype; $a_{1}, a_{2}, a_{3} \ldots .$. - square of the soil kind varity within the very type and subtypes; $k_{1}, k_{2}, k_{3} \ldots .$. - bonitation scale of the kind varities; Square - is the total area of the soil types and subtypes.

The advantages od the bonitation in comporison with the previous methods lead to the profitable outcomes from the resarches and selection of the suitable measurements. In study of the forest soil ecology[11,12], for improving and totalizing of the summarized outcomes bonitation has special importance.

As the next stage of the bonitation agro-producing grouping realization gives opportunity to define diagnostical properties of the forest soils and carrying out practical works. In agro-producing grouping of Shamakhi regions forest soils and soils without woodland the method $[4,5]$ put forqard by academician G.Sh.Mammadov was used. Due to the method common grouping is done to the appropriate bonitation indexes. During grouping horizontal and vertical extention of the soils, bonitation indexes, demands from the further measurements have been considered.

Then on the base of the investigated soil type and subtype bonitation agro-producing grouping was actualized.

Table. Agro-Production grouping of the soils under forests and woodless areas of Shamakhi in Azerbaijan

\begin{tabular}{|c|c|c|c|c|}
\hline \multirow{2}{*}{ Shamakhi quality group of soils } & \multirow{2}{*}{ Names of the soils } & \multirow{2}{*}{ Index } & \multicolumn{2}{|c|}{ Square } \\
\hline & & & $\mathrm{Ha}$ & $\%$ \\
\hline \multirow{2}{*}{ I group high quality soils, $100-81$ points } & Thick, typical mountain-forest brown & 100 & 392,05 & 69 \\
\hline & Medium thick, typical mountain-forest brown & 80 & 170,00 & 30 \\
\hline \multicolumn{2}{|c|}{ Agro-producing grouping average calculated index/sum } & 90 & 281,025 & 50 \\
\hline \multirow{9}{*}{ II group good quality soils, $80-61$ points } & Medium thick, typical mountain-forest brown & 80 & 170,00 & 30 \\
\hline & Medium thick, washed mountain (garden)- forest brown & 79 & 255,2 & 100 \\
\hline & Thick, woodless, washed mountain brown & 75 & 3406,75 & 71 \\
\hline & Thick, woodless, typical mountain brown & 74 & 2585,9 & 81 \\
\hline & Medium thick, carbonated mountain (garden)-mountain brown & 73 & 205,4 & 62 \\
\hline & Thick, washed, mountain-meadow-forest & 73 & 2570,58 & 42 \\
\hline & Thick, woodless carbonated mountain-brown & 67 & 12929,65 & 49 \\
\hline & Medium thck, carbonated mounatin-forest brown & 66 & 2530,00 & 62 \\
\hline & Medium thick, woodless, washed mountain brown & 60 & 1301,96 & 27 \\
\hline \multicolumn{2}{|c|}{ Agro-producing grouping average calculated index/sum } & 72 & 2883,94 & 58 \\
\hline \multirow{11}{*}{$\begin{array}{l}\text { III group middle quality soils, } \\
\qquad 60-41 \text { points }\end{array}$} & Thick, cultivated carbonated mountain brown & 60 & 4309,9 & 100 \\
\hline & Medium thick, woodless, typical mountain brown & 59 & 591,6 & 18 \\
\hline & Thick, steppe mountain brown & 59 & 5114,85 & 65 \\
\hline & Medium thick, washed, mountain-meadow-forest & 58 & 3405,7 & 55 \\
\hline & Lamella, carbonated mountain- (garden)-forest brown & 55 & 125,85 & 37 \\
\hline & Medium thick, woodless carbonated mountain brown & 54 & 7051,65 & 27 \\
\hline & Cultivated typical mountain brown & 51 & 372,7 & 100 \\
\hline & Lamella, carbonated, mountain forest brown & 49 & 1489,5 & 37 \\
\hline & Medium thick, steppe mountain brown & 47 & 1754,9 & 22 \\
\hline & Lamella, washed mountain-meadow-forest & 44 & 1763,7 & 28 \\
\hline & Lamella, woodless carbonated mountain brown & 40 & 6046,75 & 23 \\
\hline \multicolumn{2}{|c|}{ Agro-producing grouping average calculated index/sum } & 52 & 2911,55 & 45 \\
\hline IV group low quality soils, $40-21$ points & Lamella, steppe mountain brown & 35 & 984,3 & 12 \\
\hline \multicolumn{2}{|c|}{ Agro-producing grouping average calculated index/sum } & 35 & 984,3 & 12 \\
\hline
\end{tabular}




\section{Results and Discussions}

By the above mentioned formulas (1), (2) soil type and subtype final bonitation indexes were found. The very indexes have been aligned and tabled to the summarized bonitation scale's regulation, so due to the ablatitious line on eleven soil types and subtypes. Then the open bonitation scale of all soil types was established. On tha base of this bonitation all soils were divided into four agro-producing groups. In the table the bonitation indexes and squares of the soil areas were given the vertical southern slope pure oak forest During agro-producing grouping each soil type and subtype average calculated index and area average square were found. For ecological estimation study of forest and woodless soils in Shamakhi region was based on the bonitation. The next stage of this bonitation leads to the agroproducing grouping. At the same time the process lets reforestation and reafforestation realization. In the issue of the monitoring done forest hewing in Pirgulu having specific forest lines was observed. The agro-producing groping is necessary for solving the current problems appeared at this hewing process. The present forest state can be clealy seen from the photo, too

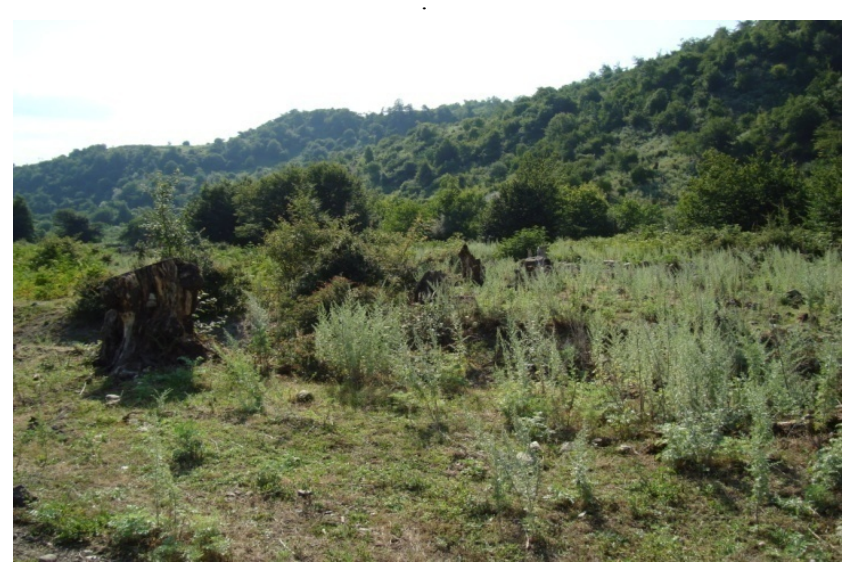

Photo. A fragment from Pirgulu forest

\section{Conclusions}

Summarizing the carried out researches, due to the outcomes from the table all soils indexes were divided into four groups and classified widely.

\subsection{Group High Quality Soils (100-81 Points)}

The highest quality soils having excellent regime and condition for cultivating forest forming tree species (oak (Quercus), hornbeam (Carpinus), beech (Fagus)) is included into the first group. Usually high quality soils have no difficulties because of forest-irrigation. Such soils possess thick humus layer, in their air-water regime is smooth, granulometric content and structure are under good condition.

The soils extended on the higher mountainous regions on alpine range, subalpine-meadow and meadow-steppe belt under annual plant and perennial plant grass plants. And on the medium or low mountainous zones these soils have been spread at the mesophile and xerophilous forests, also in various farms on the foothills, on the dry-steppe zones of the plain. In Shamakhi region square of soils included into the first group is $281,025 \mathrm{ha}$, so this consists of $50 \%$ of all region territory.

\subsection{Group Good Quality Soils (80-61 Points)}

Good quality soils included into the second group distinguishes from the first group soils with air-water regime, fruitful structure and humus content. Thus fertility showings of the second group soils are lower than the first one. This influences on the bonitation index by reducing to 80-61 points. Whilst forestation in such soils the tree and plant species selection should be fitted to the soil parameters. In the region II group good quality soils' total square is $2883,94 \mathrm{ha}$, it consists of $58 \%$ within the common land foundation.

\subsection{Group Middle Quality Soils (60-41 Points)}

These soils possess weaker showings, unsuitable content and characteristics distinguish sharply from I and II group soils. In order to use such soils proper fertilizing and technical measurements should be carried out in advance. These soils extended on the high mountainous zone under woodless meadow-steppe region. On the middle and low mountainous III group soils spread under the mesophilous and xerophilous forests. Also on the foothills and plain zones on the dry steppe fields such soils extended. In Shamaki region this soil area square is 2911,55 ha, it covers $45 \%$ of the land foundation in the region.

\subsection{Group Low Quality Soils (40-21 Points)}

The soils concerning to this group underwent several erosions (wind and water erosion), eolation, sometimes they possess salinification and salting peculiarities. With lower indexes such soils have the weakest content and features for reforestation process. In this group soil beforehand measurements are necessary as in the III group soils including fertilizing and technical ones. These soils demand more services but they are lower fertility. In the region this group soil area square is $984,3 \mathrm{ha}$, it consists $12 \%$ of land foundation in Shamakhi.

\section{REFERENCES}

[1] G.Sh.Mammadov, M.Y.Khalilov. Azerbaijan forests. Baki «Elm» 2002, p. 472

[2] G.Sh.Mammadov. Ecological estimation of Azerbaijan soils. Baki, «Elm» 1998, p. 322

[3] G.Sh.Mammadov. Eco-ethical problems of Azerbaijan. Baki, «Elm» 2004, p. 377

[4] G.Sh.Mammadov, A.B.Jafarov., F.A.Jafarov. Soil bonitation. 
Baki, «Elm» 1997, p. 303

[5] G.Sh.Mammadov, A.B.Jafarov., J.A.Shabanov. Soil Estimation. Baki, «Elm» 2009, p. 121

[6] S.Z.Mammadova. Soil reserves of Lankaran region and bonitation. Baki, «Elm» 2003, p. 114

[7] S.Z.Mammadova. Ecological estimation of Lankaran region soils and monitoring. Baki, «Elm» 2006, p. 369

[8] Samadova U.F. Solar and Wind Energy Application for the Woods and Forest Soil' s Protection // Renewable Energy Congress X, Glasgow, Scotland, 19-25 July 2008, pp 512-514
[9] Kh.N.Hasanov. Forest soils ecology and scientific basis of forestationm on the south-easten part of the Great Caucasus. Theme on d.a.s, Baki, 1995. $38 \mathrm{p}$

[10] Kh.N.Hasanov. Genetical and forestation characteristics of mountain-forest soils of Shamakhi region in Azerbaijan SSR, theme on PhD for griculture, Baki, 1964. $21 \mathrm{p}$

[11] G.M.Mammadov. Thermal phisical properties of the main typical soils on the south-easten part of the Great Caucasus. 2003, Baki, 25 p

[12] Kh.M.Mustafayev. Develeopment of erisive processes on the south slope of the Great Caucasus /within Azerbaijan SSR and basis of the fight against to it/1967, Baki. 45 